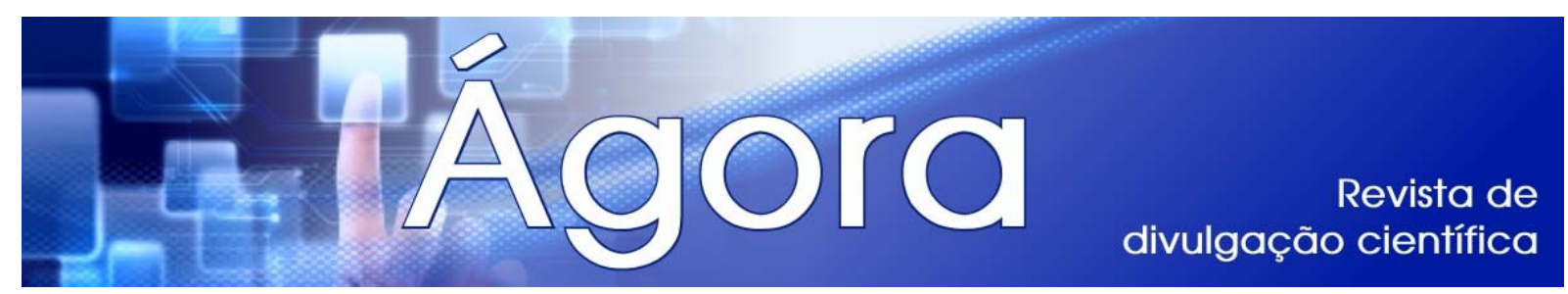

\title{
ADESÃO AO TRATAMENTO ANTI-HIPERTENSIVO: VISÃO DOS ACS E DOS USUÁRIOS DAS ESF
}

\author{
Tatiane Cubas Ribas ${ }^{1}$ \\ Salete Regina Daronco Benetti ${ }^{2}$
}

\begin{abstract}
RESUMO: Este artigo objetiva trazer a visão dos ACS e dos Pacientes hipertensos, sobre a importância de orientações e o uso correto das medicações antihipertensivas. A hipertensão é um grave problema de saúde pública, sendo uma doença crônica que se não tratada adequadamente pode ocasionar várias complicações. Os ACS são moradores da comunidade onde atuam, identificados com a mesma, possuidores dos mesmos costumes, valores e linguagem e são selecionados, capacitados e acompanhados pela equipe de saúde, de acordo com os requisitos estabelecidos pelo Ministério da Saúde. Seu trabalho é baseado em ações educativas e preventivas que buscam fortalecer a organização, a valorização e o desenvolvimento comunitário. Os ACS têm como uma de suas atribuições a distribuição dos medicamentos para as famílias de sua área, dentre eles os antihipertensivos, ajudando numa melhor adesão ao tratamento. Sabe-se que uma grande parte dos pacientes que utilizam medicações contínuas, principalmente antihipertensivas, são os idosos que, certamente, apresentam uma maior dificuldade no entendimento e compreensão relacionado a importância da utilização de tal medicamento. A pesquisa foi realizada no mês de setembro de 2012, com 23 Agentes Comunitários de Saúde (ACS) e 40 hipertensos acima de 50 anos, inseridos na Estratégia saúde da família de um município do sul do estado do Paraná.
\end{abstract}

Palavras chaves: Agente comunitário de saúde. Adesão. Hipertensos. Medicações. Enfermagem.

ABSTRACT: This article aims to bring the vision of the ACS and Hypertensive patients on the importance of guidance and proper use of antihypertensive medications. Hypertension is a serious public health problem, being a chronic disease that if not treated properly can lead to various complications. The ACS are residents of the community where they operate, identified with the same owners of the same customs, values and language are selected, trained and monitored by the health care team, according to the requirements set by the Ministry of Health His work is based on educational and preventive actions that seek to strengthen the

\footnotetext{
${ }^{1}$ Acadêmica do Curso de Enfermagem da Universidade do Contestado. E-mail: tati t.c.r@hotmail.com ${ }^{2}$ Mestre em Enfermagem pela Universidade Federal do Paraná (UFPR). Docente da Universidade do Contestado (UnC), Campus Canoinhas/SC. Membro do Grupo Multiprofissional de Pesquisa sobre Idosos (GMPI) E-mail: saleterdb@yahoo.com.br
}

Ágora: R. Divulg. Cient., v. 18, n. 2, p. 2-29, dez. 2011 (ISSN 2237-9010) 
organization, appreciation and community development. The ACS has as one of its tasks the distribution of medicines to families in their area, including antihypertensives, helping in better treatment adherence. It is known that a large proportion of patients using continuous medications, especially antihypertensive, are seniors who certainly have greater difficulty in understanding the importance and understanding related to the use of this medicine. The survey was conducted in September 2012, with 23 Community Health Agents (ACS) and 40 hypertensives over age 50, entered the Family Health Strategy in a city in the southern state of Paraná.

Keywords: Community health agent. Accession. Hypertensives. Medications. Nursing.

\section{INTRODUÇÃO}

A Estratégia Saúde da Família - ESF tem por objetivo prestar assistência de saúde em domicílio, e assim intervir sobre fatores de risco a que a população está exposta. Essa proposta foi criada como Programa Saúde da Família em 1994, quando da descentralização e da municipalização dos serviços de saúde e que era um desafio à implementação efetiva do SUS. O programa do Ministério da Saúde tenta valorizar esses princípios sendo: territorialização, vinculação com a população, garantia de integridade na atenção, trabalho em equipe com o enfoque interdisciplinar, estímulo à participação da comunidade dando ênfase à promoção da saúde, com fortalecimento das ações inter-setoriais (FIGUEIREDO, 2005).

O programa de agentes Comunitários de saúde (PACS), visando a saúde coletiva, surgiu para compor as equipes de saúde da família, provocando mudança significativa no processo de trabalho em saúde (GUEDES, SANTOS, LORENZO 2011).

Os agentes comunitários de saúde (ACS) têm como uma de suas atribuições a distribuição dos medicamentos para as famílias de sua área, dentre eles os antihipertensivos, ajudando numa melhor adesão do paciente ao tratamento.

Sabe-se que uma grande parte dos pacientes que utilizam medicações contínuas, principalmente anti-hipertensivas, são os idosos que, certamente apresentam uma maior dificuldade no entendimento e compreensão relacionado a importância da utilização de tal medicamento. 
As orientações fornecidas pelos ACS são de grande importância, pois eles estão mais próximos dos pacientes do que a própria enfermeira da ESF, pois devido a demanda de serviços na unidade, a enfermeira não tem disponibilidade de tempo para realizar visitas domiciliares a todas as famílias, assim os ACS acabam criando um vínculo muito forte com essas famílias, servindo muitas vezes de referência.

Embora concorde-se com alguns autores como Tomaz (2002, p. 86), quando afirma que: "não existe uma clara delimitação das atribuições do ACS, seu papel tem sido distorcido, pois qualquer ação que deva ser desenvolvida nas famílias e na comunidade é atribuída ao ACS, sobrecarregando, na maioria das vezes, o seu trabalho".

\section{ESTRATÉGIA SAÚDE DA FAMÍLIA (ESF)}

O Programa Saúde da Família foi constituído para que houvesse a implementação à atenção básica e o fortalecimento do Sistema Único de Saúde SUS, criado pela Constituição Brasileira de 1988, regulamentado posteriormente, em 1990, pelas Leis Orgânicas da Saúde 8080 e 8142, assegurando uma nova lógica assistencial. O novo modelo abrange ações tendo o foco na família, de proteção, promoção e recuperação da saúde, garantindo à população uma assistência de qualidade e eficaz. (BRASIL, 2006 apud SHIMIZU; ROSALES, 2009).

Atualmente, segundo o Ministério da Saúde (BRASIL, 2012), o PSF é definido como Estratégia saúde da Família, ao invés de programa, sendo que programa indica um começo meio e fim, e ESF sendo uma estratégia de reorganização da atenção primaria não prevê um tempo para sua finalização, propondo que a estratégia seja sempre continuada.

\footnotetext{
A Saúde da Família é entendida como uma estratégia de reorientação do modelo assistencial, operacionalizada mediante a implantação de equipes multiprofissionais em unidades básicas de saúde. Estas equipes são responsáveis pelo acompanhamento de um número definido de famílias, localizadas em uma área geográfica delimitada. As equipes atuam com ações de promoção da saúde, prevenção, recuperação, reabilitação de doenças e agravos mais frequentes, e na manutenção da saúde desta comunidade (BRASIL, 2012, p. 1).
}

A ESF, propõe novas práticas sanitárias norteadas pelos princípios do SUS contemplando a participação popular e, consequentemente, a reformulação dos 
conceitos de saúde, doença, população e práticas. Destaca-se que as práticas de saúde vão além das intervenções curativas, devendo ser direcionadas não para atender, mas para prevenir a doença e promover a saúde.

A ESF é composta por uma equipe multidisciplinar que trabalha com uma área composta de no máximo 4.500 pessoas, sendo responsável por dar aporte às famílias de sua área adscrita, inseridos neste contexto estão os ACS que são responsáveis por realizar visitas a essas famílias e dentre suas funções está a de realizar as entregas de medicações para pessoas que fazem uso de medicações continuas, nesse momento é que se realizam as orientações quanto a adesão medicamentosa, e o agendamento de consultas quando há necessidade (BRASIL, 1997).

\title{
PROGRAMA DE AGENTES COMUNITÁRIOS DE SAÚDE - PACS
}

Entre todas as conquistas do SUS:

\begin{abstract}
Em 1991 e 1994, o Ministério da Saúde preocupado em fazer uma medicina coletiva mais do que individual lança, respectivamente, o Programa Agente Comunitário de Saúde (PACS), o Programa Saúde da Família (PSF) e posteriormente a Estratégia Saúde da Família (ESF), como novas formas de fazer saúde na comunidade, ou seja, fazer saúde com envolvimento e mudança de postura dos atores sociais aqui compreendidos como clientela, profissionais do serviço, gerentes, planejadores, serviços de contra referência ou apoio envolvidos de forma significativa com a realidade dos usuários do sistema de saúde (JUGDAR et al., 2009, p. 38).
\end{abstract}

De acordo com Silva (1997 apud GUIMARÃES et al., 2007) o agente de saúde teria o papel de facilitar o autocuidado, identificando demandas que necessitavam de atendimento, principalmente a atenção às crianças para debelar a mortalidade infantil. Em 1991, o Ministério da Saúde instituiu o Programa Agente Comunitário de Saúde (PACS) em outros municípios do país tendo como base a experiência do Ceará com o PAS.

Mais tarde o governo instituiu o PSF (Programa Saúde da família) sendo em 1994, tendo como objetivo ampliar a atuação do PACS, construindo uma parceria de trabalho na qual um programa interagiria com o outro, facilitando e complementando sua atuação (MARQUES; SILVA 2004). 
O PACS foi um programa audacioso, que procurou aproximar efetivamente a população, principalmente carente, dos atendimentos de saúde disponíveis no município e até mesmo encaminhamento para centros especializados quando o caso assim o exigir.

\section{AGENTES COMUNITÁRIOS DE SAÚDE}

Os agentes comunitários de saúde têm uma responsabilidade muito grande diante da manutenção da saúde familiar, bem como comunitária, além de agir diretamente na prevenção de doenças específicas e endêmicas, de acordo com as realidades em que estão inseridos (BRASIL, 2009).

Os ACS são moradores da comunidade onde atuam, identificados com a mesma, possuidores dos mesmos costumes, valores e linguagem e são selecionados, capacitados e acompanhados pela equipe de saúde, de acordo com os requisitos estabelecidos pelo Ministério da Saúde. Seu trabalho é baseado em ações educativas e preventivas que buscam fortalecer a organização, a valorização e o desenvolvimento comunitário, sendo considerado por alguns autores como "a mola propulsora" para a consolidação do SUS.

O trabalho dos ACS exige grande cautela e conhecimentos, não só de seus deveres enquanto profissionais, mas também com relação ao relacionamento e vínculos criados com as famílias que atendem. Diante do trabalho realizado, o ACS conquista a confiança por parte das famílias que atendem (BRASIL, 2009).

É importante que os ACS tenham a oportunidade de participar de cursos de aperfeiçoamento e/ou treinamento quanto ao uso de medicamentos, em especial, dos medicamentos anti-hipertensivos, que são entregues à população de sua área de abrangência. Além da entrega desses medicamentos, os ACS precisam orientar o uso correto dos anti hipertensivos, pois em muitos casos são pessoas idosas que já apresentam dificuldade na leitura e na memória em relação às orientações dadas pelo médico, bem como se organizar nos horários e de que forma devem tomá-los (BRASIL, 2009).

Dentro deste contexto, cabe à equipe de saúde, sobretudo ao enfermeiro instrutor/coordenador, possibilitar aos ACS um constante processo de 
construção/reconstrução de seu aprendizado, proporcionando suporte para sua atuação.

Segundo a lei $\mathrm{N}^{\circ}$ 11.350, de 5 de Outubro de 2006 (BRASIL, 2006, p. 01), referente ao artigo $3^{\circ}$ :

\footnotetext{
O Agente Comunitário de Saúde tem como atribuição o exercício de atividades de prevenção de doenças e promoção da saúde, mediante ações domiciliares ou comunitárias, individuais ou coletivas, desenvolvidas em conformidade com as diretrizes do SUS e sob supervisão do gestor municipal, distrital, estadual ou federal.

Parágrafo único. São consideradas atividades do Agente Comunitário de Saúde, na sua área de atuação:

I - a utilização de instrumentos para diagnóstico demográfico e sociocultural da comunidade;

II - a promoção de ações de educação para a saúde individual e coletiva;

III - o registro, para fins exclusivos de controle e planejamento das ações de saúde, de nascimentos, óbitos, doenças e outros agravos à saúde;

IV - o estímulo à participação da comunidade nas políticas públicas voltadas para a área da saúde;

$\mathrm{V}$ - a realização de visitas domiciliares periódicas para monitoramento de situações de risco à família; e

VI - a participação em ações que fortaleçam os elos entre o setor saúde e outras políticas que promovam a qualidade de vida.
}

Esta lei (N 11350, de 05/10/2006) ampara os direitos e deveres dos agentes comunitários de saúde, no artigo $3^{\circ}$ fica claro sobre a importância das ações desenvolvidas na comunidade, pois de que adiantaria os ACS realizarem visitas domiciliares se não para desenvolver ações de promoção de saúde e prevenção de doenças.

Primeiramente o ACS deve conhecer o perfil-sociocultural dos usuários de sua área, para assim saber como abordar melhor aquela família ou o individuo, é seu dever também registrar os dados de nascimentos, óbitos, doenças e outros agravos à saúde, incluindo-se neste contesto os hipertensos que devem ser registrados e acompanhados pela equipe multiprofissional, cabe também estimular a comunidade em participar de ações estratégicas para prevenção e promoção de saúde que geralmente são realizadas pela equipe de ESF, como estratégia principal a realização de visitas domiciliares onde assim consegue observar a necessidade de cada família (BRASIL, 2006).

Segundo o Ministério da Saúde (BRASIL, 2002), para que o ACS execute seu trabalho ele deve ter habilidades (saber fazer) como trabalhar em equipe de saúde, promover a integração entre a equipe de saúde e a população de referência adscrita 
à unidade básica de Saúde, identificar a importância do acompanhamento da família no domicílio como base para o desenvolvimento de suas ações, orientar indivíduos, famílias e grupos sociais quanto aos fluxos, rotinas e ações desenvolvidas no âmbito da atenção básica de saúde, realizar ações de coleta de dados e registro das informações pertinentes ao trabalho desenvolvido.

Em relação às pessoas que têm a hipertensão arterial diagnosticada a responsabilidade do agente comunitário de saúde, segundo o Ministério da Saúde (BRASIL, 2009, p. 105-106), é:

- Identificar os hipertensos de sua área de atuação e preencher a ficha BHA do SIAB (Sistema de Informação de Atenção Básica);

- Verificar o comparecimento às consultas agendadas na UBS;

- Realizar busca ativa dos faltosos;

- Perguntar, sempre, à pessoa com hipertensão e que tenha medicamentos prescritos se está os tomando com regularidade. Se houver dificuldades nesse processo, informar à equipe quais são e planejar ações de enfrentamento;

- Estimular o desenvolvimento de hábitos de vida saudável: se está cumprindo as orientações de dieta, atividade física,

- controle de peso, se reduziu ou parou de fumar e de consumir bebidas alcoólicas;

- Estimular a adoção de hábitos alimentares saudáveis, com baixo teor de sal, baseados em frutas, verduras, derivados de leite desnatado;

- Orientar a redução do consumo de bebidas alcoólicas ou seu abandono;

- Orientar sobre a importância da adesão ao tratamento e seguir as orientações da equipe de saúde;

- Estimular a realização de atividades físicas regulares;

- Estimular a participação em grupos de autoajuda;

- Fazer acompanhamento da pressão arterial conforme orientação da equipe de saúde.

O ACS é um profissional importantíssimo na prevenção de doenças, pois é o elo entre o paciente e a equipe de saúde. De acordo com Fortes e Spinetti (2004, p.5) "a presença do ACS como elemento da equipe saúde da família traz contribuição fundamental nas relações com os usuários do sistema público de saúde".

\section{HIPERTENSÃO ARTERIAL}

Hipertensão ou pressão alta é uma condição em que a pressão do sangue nas artérias é cronicamente elevada. De acordo com Cornu (2012, p. 2), cada batida do coração é responsável pelo bombeamento do sangue para todo o corpo, a 
pressão arterial é a força do sangue que está empurrando-se contra as paredes dos vasos sanguíneos. Se a pressão for muito alta, o coração tem que trabalhar mais para bombear, e isso pode levar a danos nos órgãos e a várias doenças, tais como: ataque cardíaco, insuficiência cardíaca, aneurisma, ou insuficiência renal.

O nível normal de pressão de sangue deve estar abaixo ou igual a 120/80, em que 120 representa a medida sistólica (pressão de pico nas artérias) e 80 representa a medida diastólica (pressão mínima nas artérias). A pressão arterial entre 120/80 e 139/89 é chamado pré-hipertensão (para indicar um risco aumentado de hipertensão), e uma pressão sanguínea de 140/90 ou superior é considerada hipertensão (CORNU, 2012).

Costa e Carvalho (2005, p. 152) relatam que a prevalência crescente da obesidade é um dos fatores de risco mais importantes para o desenvolvimento da hipertensão. Esta epidemia de obesidade, além de estar diretamente ligada as causas da hipertensão, inclusive em crianças e adolescentes também podem provocar outros danos à saúde como diabetes e doença renal crônica.

\section{METODOLOGIA}

Trata-se de uma pesquisa de campo, de natureza básica, com abordagem qualitativa e finalidade exploratória.

Segundo Bervian e Cervo (1996), a pesquisa é uma atividade voltada para a solução de problemas, através do emprego de processos científicos.

Segundo Oliveira (2002), as pesquisas qualitativas possuem a facilidade de poder descrever a complexidade de uma determinada hipótese ou problema, analisar a interação de certas variáveis, compreender e classificar processos dinâmicos experimentados por grupos sociais, apresentar contribuições nos processos de mudanças, criação ou formação de opiniões de determinado grupo.

De acordo com Oliveira (2002), a pesquisa exploratória dá ênfase à descoberta de práticas ou diretrizes que precisam modificar-se e na elaboração de alternativas que possam ser substituídas. Esse tipo de pesquisa possibilita localizar pessoas informadas, semi-informadas ou desinformadas a respeito do assunto que está sendo objeto de pesquisa. 


\section{LOCAL DA PESQUISA}

Esta pesquisa foi realizada em um município, situado na região Sudeste do estado do Paraná. O município tem uma área total de $284,49 \mathrm{~km}^{2}$ e possui segundo os dados do IBGE (2000) 10.000 habitantes. É uma região predominante de floresta nativa, com economia agrícola e industrial.

No município existem 03 ESF e 01 PACS. A unidade básica do estudo realiza a função da ESF no centro, porém é responsável por um total 12 unidades básicas de saúde distribuídas pelas comunidades do interior.

\section{POPULAÇÃO/AMOSTRA}

O universo da pesquisa foram os pacientes hipertensos e os ACS da estratégia saúde da família. As três ESF do estudo contam atualmente com 1.513 pacientes portadores de Hipertensão Arterial, cadastrados e acompanhados no programa do Ministério da Saúde denominado HiperDia.

Para realização desta pesquisa foi utilizado como critério de inclusão: 01 ESF; os agentes comunitárias de saúde que compõem todas as equipes das ESFs; $20 \%$ (40) dos pacientes hipertensos da ESF central (PACS); de ambos os gêneros e maiores de 50 anos; que sejam cadastrados no programa HiperDia, e que concordassem em participar da pesquisa e assinar o termo de consentimento livre e esclarecido, conforme Resolução 196/96, CNS/MS (BRASIL, 1996).

De acordo com Oliveira, (2002), amostra é uma porção ou parcela, selecionada do universo (população). Universo e população é o conjunto de seres animados ou inanimados que representam pelo menos uma característica em comum. 


\section{RESULTADOS}

\section{RESULTADOS DA PESQUISA COM OS AGENTES COMUNITÁRIOS DE SAÚDE}

Tabela 1 - Caracterização dos ACS segundo idade, gênero, escolaridade e tempo de atuação

\begin{tabular}{c|l|c|c}
\hline Grupo & Caracterização & $\mathrm{N}^{\circ}$ & $\%$ \\
\hline \multirow{3}{*}{ Idade } & De 20 a 30 anos & 10 & 43,5 \\
& De 30 a 40 anos & 9 & 39,10 \\
& Mais de 40 anos & 4 & 17,40 \\
\hline \multirow{3}{*}{ Gênero } & Masculino & 01 & 4,35 \\
& Feminino & 22 & 95,65 \\
\hline \multirow{5}{*}{ Escolaridade } & Analfabeto & 00 & 00 \\
& Ensino fundamental Inc. & 01 & 4,35 \\
& Ensino fundamental Comp. & 04 & 17,39 \\
& Ensino Médio Incompleto & 04 & 17,39 \\
& Ensino Médio Completo & 11 & 47,82 \\
& Superior Incompleto & 02 & 8,69 \\
& Superior Completo & 01 & 4,35 \\
\hline \multirow{5}{*}{ Tempo de } & A menos de 1 ano & 01 & 4,35 \\
Atuação & De 1 a 2 anos & 02 & 8,69 \\
& De 2 a 4 anos & 06 & 26,08 \\
& De 4 a 6 anos & 02 & 8,69 \\
& De 6 a 8 anos & 08 & 34,78 \\
& De 8 a 10 anos & 02 & 8,69 \\
& Mais de 10 anos & 02 & 8,69 \\
\hline
\end{tabular}

Fonte: Dados da pesquisa (2012)

$\mathrm{Na}$ tabela 1, verifica-se que a faixa etária predominante dos ACS, está entre 20 e 30 anos, contando com um percentual de 43,5\% ( $n=10)$; em relação ao gênero, o feminino constitui 95,65\% $(n=22)$ sendo 4,35\% $(n=01)$ do gênero masculino.

A maioria dos ACS pertencerem ao gênero feminino pode ser atribuída ao fato de ser um trabalho mais leve, sem exigir muito esforço físico, caracterizada pela visita domiciliar e, talvez pela questão salarial (um salário mínimo), pois o homem como provedor da maioria dos lares tende a procurar uma remuneração maior.

Quanto ao grau de escolaridade, pode-se constatar uma ACS que não corresponde às exigências do Ministério da Saúde, pois não possui o ensino fundamental completo. O resultado predominante foi que 47,82\% ( $n=11)$ dos participantes possui o ensino médio completo, isso indica que podem ter um melhor entendimento em relação às orientações oferecidas pelo enfermeiro e, consequentemente, poderão orientar melhor os usuários.

Albuquerque et al. (2005), diz que a seleção dos ACS segue com os seguintes critérios: os candidatos devem ser moradores dos bairros contemplados 
pelo programa; é exigido, como escolaridade mínima, o Ensino Fundamental; os candidatos devem realizar prova escrita sobre situações cotidianas e entrevista.

Assim, acredita-se que deve ter ocorrido alguma situação extraordinária, que não foi investigada pela pesquisadora, para que uma pessoa, sem ter concluído o ensino fundamental, esteja atuando como ACS.

Em relação ao tempo de atuação como ACS observa-se que a predominância é de 6 a 8 anos, 34,78\% (n=8), acredita-se que devido ao tempo de atuação da maioria ser maior que 02 anos, devem ter um maior conhecimento sobre suas atribuições e sobre o que devem orientar.

Gráfico 1 - Referente a conduta tomada ao identificar um hipertenso que se nega a realizar o tratamento anti-hipertensivo

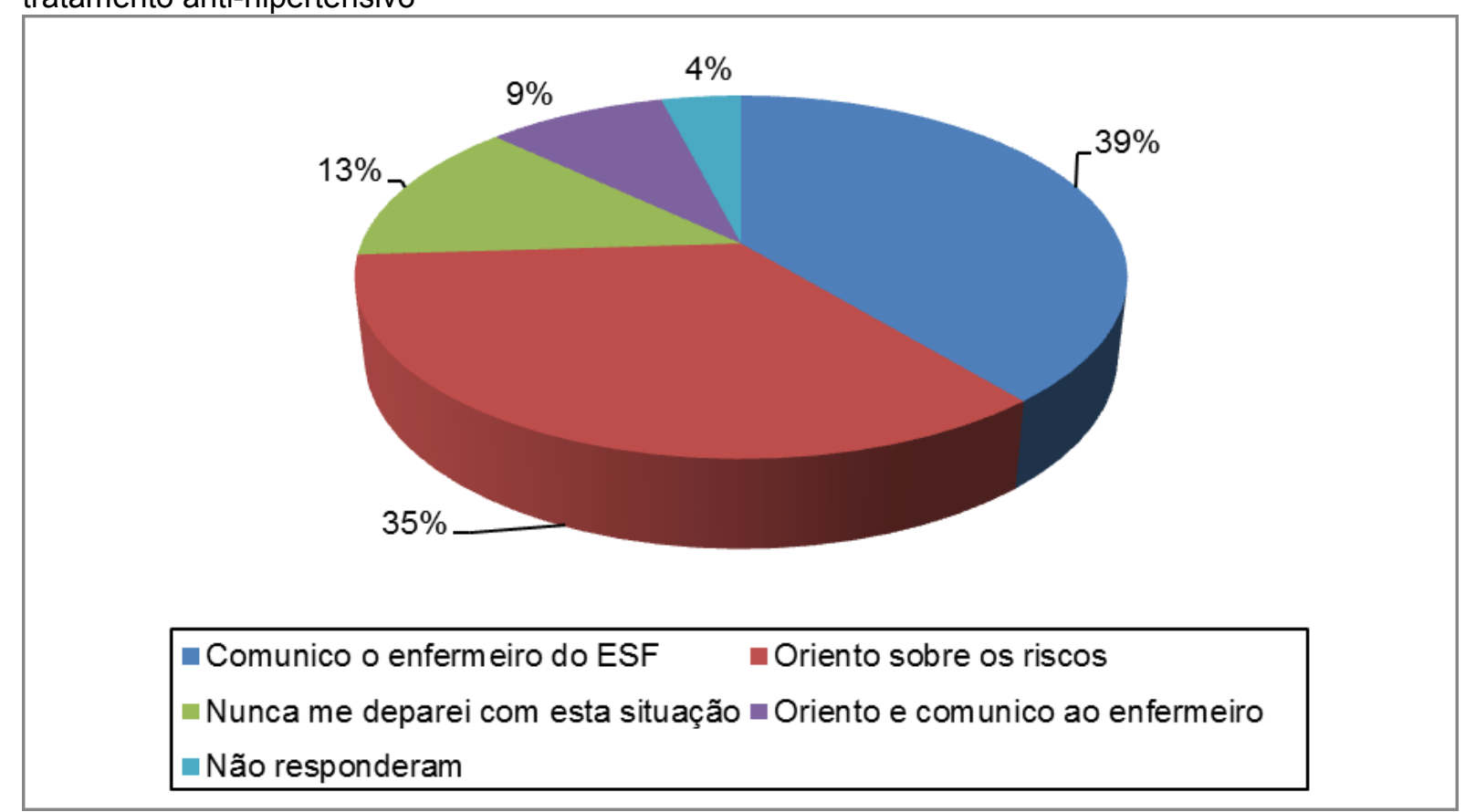

Fonte: Dados da pesquisa (2012)

Nota-se que as respostas mais significativas foram orientar o hipertenso e comunicar o enfermeiro. Detalhando tem-se que: em caso de pacientes que se negam a realizar o tratamento medicamentoso, 35\% $(n=8)$ dos ACS procuram orientar sobre os riscos de não realizar o tratamento anti-hipertensivo; já $39 \%(n=9)$ responderam que a conduta tomada é comunicar o enfermeiro de sua ESF, para assim discutirem juntos e resolver o problema; 13\% $(n=3)$ dizem nunca ter se deparado com esse tipo de situação; $9 \%(n=2)$ dizem orientar e comunicar ao enfermeiro e $4 \%(n=1)$ não respondeu. 
De acordo com Takahashi e Oliveira (2001 apud LIMA, SILVA e BOUSSO, 2010), a visita domiciliar é definida como uma estratégia de intervenção na Saúde da Família, utilizada pelos integrantes da equipe para conhecer as condições de vida e de saúde das famílias que estão sob sua responsabilidade dentro de sua área.

De acordo com o Ministério da Saúde, o trabalho do ACS deve ser valorizado e incentivado, pois lhe são designados funções estratégicas e complexas, sendo direcionado pelo contato direto com a população. Dentre suas atribuições está: realizar o mapeamento de sua área de atuação, cadastrar e acompanhar as famílias de sua micro área, saber identificar situações de risco, desenvolver ações de prevenção e promoção de saúde, promover a educação á saúde e a mobilização comunitária mediante ações de saneamento básico e prevenção do meio ambiente, orientar as famílias sobre a utilização correta dos serviços de saúde, informar os demais membros da equipe sobre a dinâmica social da comunidade e participar do processo de planejamento das ações com vistas a superação dos problemas encontrados (BRASIL, 1997 apud HILDEBRAND; SHIMIZU, 2008).

A falta de adesão ao tratamento anti-hipertensivo continua sendo um dos maiores problemas encontrados entre os hipertensos, isto é muito preocupante e exige atenção dos profissionais, pois a hipertensão é uma doença altamente prevalente tanto nos países desenvolvidos como naqueles em desenvolvimento, atingindo cerca de 15 a $20 \%$ da população adulta em nosso país (BRASIL, 1993 apud SARQUIS, 1998).

Gráfico 2 - Referente as dificuldades encontradas pelos ACS quanto às orientações para adesão ao tratamento anti-hipertensivo

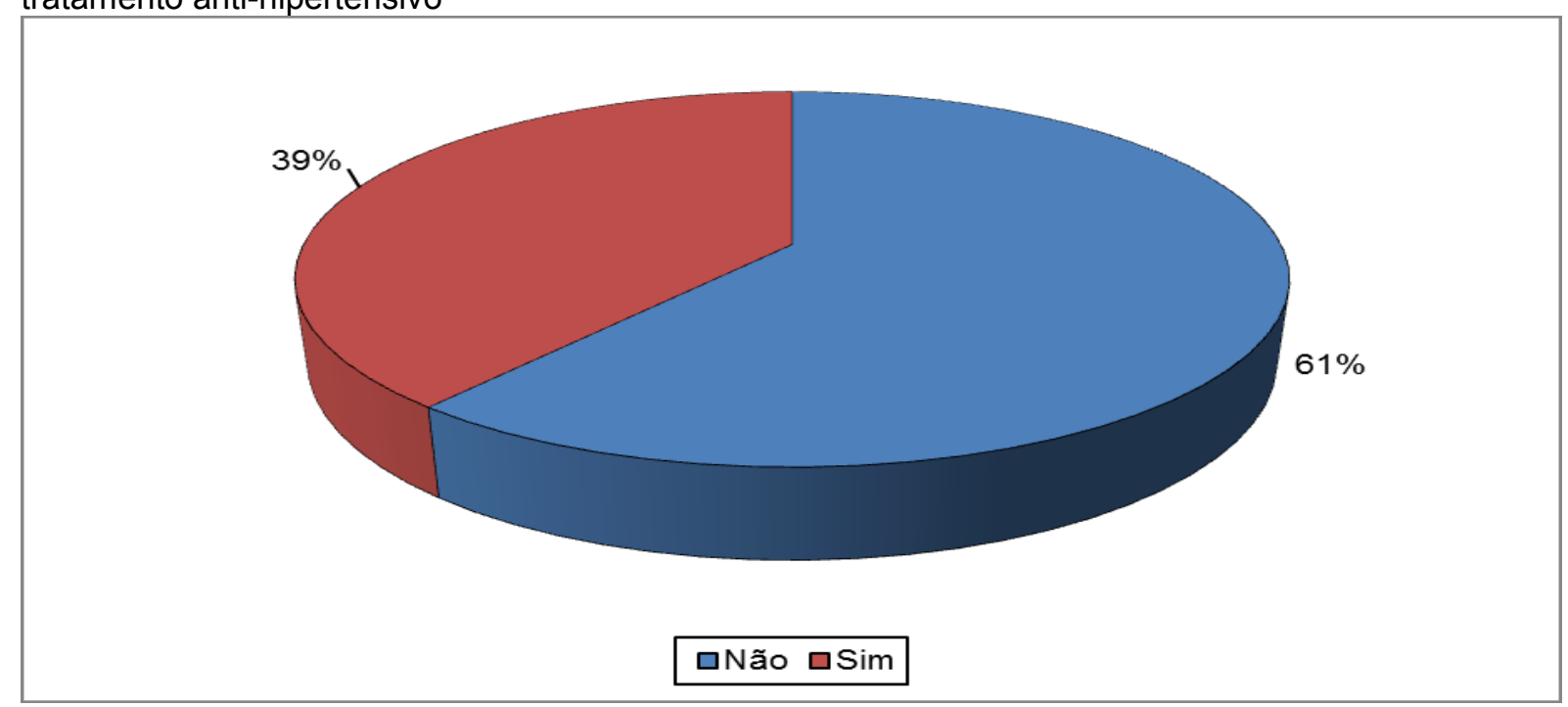

Fonte: Dados da pesquisa (2012)

Ágora: R. Divulg. Cient., v. 18, n. 2, p. 2-29, dez. 2011 (ISSN 2237-9010) 
Neste gráfico observa-se um percentual de $61 \%(n=14)$ de ACS que dizem não encontrar dificuldades em orientar os hipertensos para realizar o tratamento medicamentoso; 33\% $(n=9)$ responderam que encontram dificuldades em orientar, conforme mostram as respostas transcritas a seguir:

"Sim, pois nem sempre temos o conhecimento suficiente para uma orientação ao paciente" (Entrevistado №12. Set., 2012, Sic).

"Sim, porque às vezes não sabem tomar corretamente, moram sozinhos e não sabem ler" (Entrevistado №13. Set., 2012, Sic).

"Sim, apenas nos casos em que o hipertenso faz uso de bebida alcoólica, dai resistem ao uso do medicamento" (Entrevistado N¹4. Set., 2012, Sic).

"Sim, muitos não admitem que são hipertensos" (Entrevistado Nº16. Set., 2012, Sic).

Segundo Araújo (2006 apud SARQUIS, 1998), o nível de escolaridade influi diretamente no entendimento das orientações relacionado à doença, portanto, quanto mais baixa a escolaridade, mais difícil se torna compreender o diagnóstico, a necessidade da mudança de hábitos a as necessidades de cada patologia. Indivíduos com baixo nível de escolaridade podem ter dificuldades em compreender as orientações fornecidas pelos profissionais de saúde ou pelos ACS e, consequentemente, não aderir satisfatoriamente ao tratamento.

Monteiro (2007 apud GUEDES, 2011), afirma que portadores de hipertensão arterial vêm a abandonar o tratamento em casos de desaparecimento de sintomas.

Guedes (2011) destaca que entre os entrevistados, em sua pesquisa, são comuns afirmações em que não faz sentido manter-se em dieta alimentar reduzindo o sódio, nem deixar de ingerir bebida alcoólica, e nem realizar atividade física todos os dias, se não apresenta nenhum sintoma, dando-lhes a falsa ideia de estarem curados.

As afirmações dos autores, citados no parágrafo anterior, coincidem com as dificuldades encontradas pelos ACS demonstrados no gráfico 2, quando relatam que sentem dificuldades sim em contribuir na adesão medicamentosa no caso de pacientes alcoólatras e pacientes que não admitem que são hipertensos.

De acordo com Silva (2008 apud GUEDES, 2011), o tratamento da hipertensão arterial e as mudanças no estilo de vida acabam gerando influencia na adesão, pois os portadores ao se depararem com a doença precisam pensar em 
como modificar seus hábitos de vida, isso exige esforços, perseveranças e apoio familiar, amigos e profissionais de saúde. Se o paciente obtiver estas iniciativas estará contribuindo para a formação de hábitos saudáveis relacionado com a nova condição de saúde e de vida, com vistas á adesão total do tratamento.

De acordo com Toledo (2007 apud MOURA, 2011), estas situações têm contribuído para aumentar os custos do Sistema de Saúde. No Brasil, ocorreram cerca de 150.000 internações por doenças cardiovasculares, com custo global de 475 milhões de reais. As consequências da não adesão ao tratamento da hipertensão arterial contribuem para o aumento dos custos sociais com absenteísmo ao trabalho, licenças para tratamento de saúde, aposentadorias precoces por invalidez. Isto é confirmado por Santos (2005 apud MOURA, 2011), quando afirma que a não adesão ao tratamento resulta, consequentemente, em mais internações, óbitos e comprometimento da qualidade de vida dos grupos sociais mais vulneráveis.

Gráfico 3 - Referente à capacitação oferecida aos ACS pelos enfermeiros das ESFs

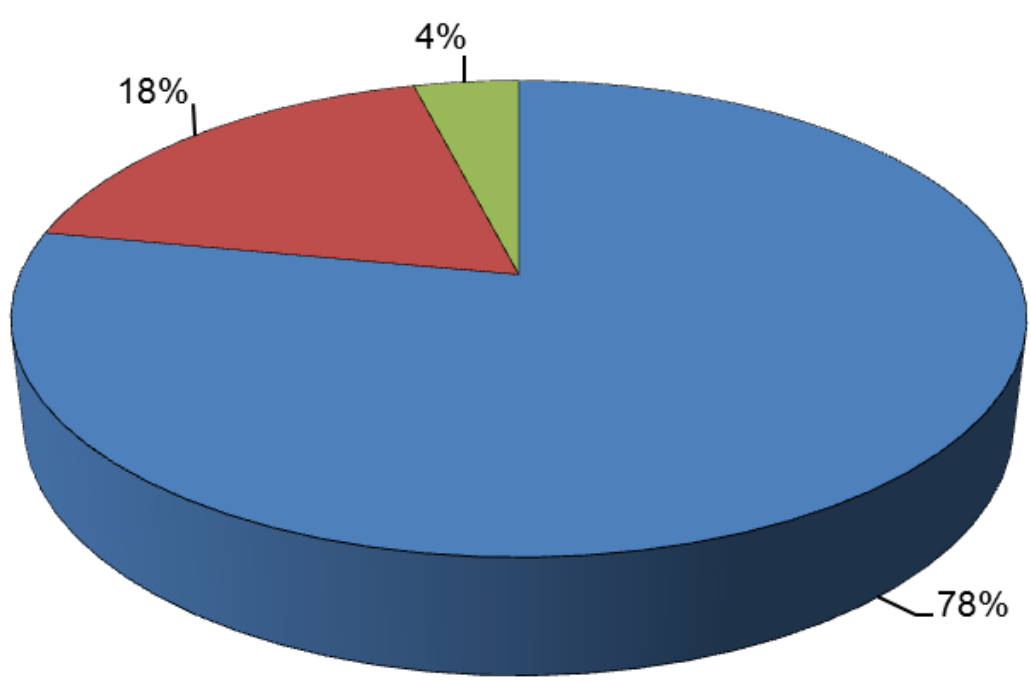

口Sim aNão $\square$ As vezes

Fonte: Dados da pesquisa (2012)

Em relação às capacitações oferecidas pelos enfermeiros aos ACS, para que melhor possam orientar os hipertensos à aderir ao tratamento medicamentoso, observa-se no gráfico 03 que $78 \%(n=18)$ dos ACS responderam que o enfermeiro de sua ESF realiza capacitações para que possam prestar um melhor atendimento 
aos usuários, isso mostra que os enfermeiros compreendem a necessidade e a importância de realizar educação continuada com sua equipe, conscientes de que precisam e devem trabalhar em conjunto; $18 \%(n=4)$ responderam que não recebem capacitação; $4 \%(n=1)$ respondeu que as vezes tem capacitação.

No dia-a-dia de trabalho os profissionais da estratégia saúde da família, vem se deparando com muitos desafios. Dentre eles, a capacitação dos profissionais de saúde, pois o conhecimento, atitudes e habilidades, constituem a base principal para o crescimento e desenvolvimento da qualidade dos serviços prestados para a população. Trabalhar com o aprendizado de diferentes profissionais torna-se mais difícil, quando se considera que a pessoa tem diferentes formas de pensar e valores ligados à sua historia de vida. Entre esses profissionais está o ACS, que conhece mais do que ninguém, a comunidade que atua, pois pertence a ela e a representa dentro do serviço (CHIESA, 2004 apud BARBOSA, FERREIRA; BARBOSA, 2012).

Uma das atribuições do enfermeiro é supervisionar, coordenar e realizar atividades de educação em saúde diretamente para os ACS e a equipe de enfermagem, com a visão de qualificar o trabalho desses profissionais (BRASIL 2006 apud BARBOSA, FERREIRA; BARBOSA, 2012).

Gráfico 4 - Referente às orientações oferecidas aos hipertensos pelos ACS

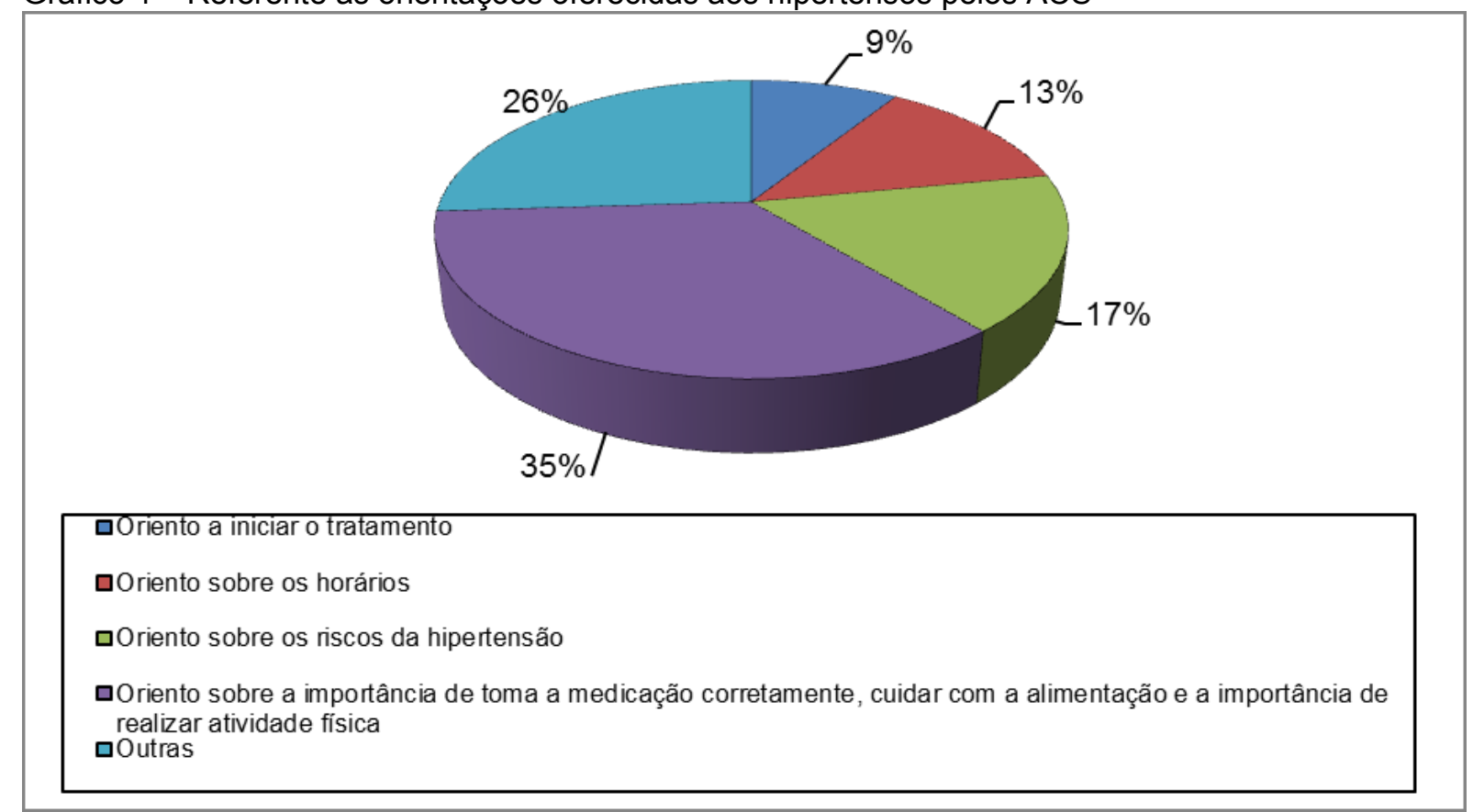

Fonte: Dados da pesquisa (2012) 
As respostas à questão sobre o que os ACS orientam aos hipertensos estão demonstradas no gráfico 4, sendo que 100\% ( $n=23)$ realizam orientações Mais uma vez destaca-se a importância de capacitar os ACS, pois direta ou indiretamente os mesmos realizam orientações, as quais dizem respeito às ações educativas que devem realizar individual ou coletivamente.

Observando-se o gráfico 04 , nota-se também que $32 \% \quad(n=8)$ dos ACS realizam orientações para os hipertensos sobre a importância de tomar as medicações corretamente, sobre os cuidados com a alimentação e a importância de praticar atividades físicas regularmente, demonstrando que alguns têm certo conhecimento sobre o assunto.

Nota-se, também, que $18 \%(n=4)$ orientam somente sobre os riscos da hipertensão; $14 \%(\mathrm{n}=3)$ orientam sobre os horários corretos para tomar a medicação, e outros $9 \%(n=2)$ orientam a iniciarem o tratamento. Estas informações restritas podem estar associadas ao fato de não terem conhecimento suficiente para demais orientações. E outros $27 \%(n=6)$ não tiveram respostas significativas.

Segundo o Ministério da Saúde (BRASIL, 2002 apud SAKATA; MISHIMA, 2012) o ACS é um trabalhador que surgiu no estado do Ceará em 1987, e hoje está inserido na equipe saúde da família, exercendo uma categoria profissional caracterizada pela execução de atividades de prevenção de doenças e promoção de saúde. Destaca-se que sua principal atividade é realizar visitas domiciliares, seguida de educação em saúde com orientações sobre higiene, calendário vacinal, uso correto de medicamentos, cuidados com recém-nascidos, gestantes e puérperas (FERRAZ, 2005 apud SAKATA; MISHIMA, 2012).

\section{RESULTADOS DA PESQUISA COM OS HIPERTENSOS}

Tabela 2 - Descrição dos Hipertensos segundo a idade, gênero, escolaridade, estado civil, ocupação, renda media mensal e composição familiar dos Hipertensos

\begin{tabular}{|c|c|c|c|}
\hline & & & Continua... \\
\hline Grupo & Caracterização & $\mathbf{N}^{\circ}$ Hipertensos & $\%$ \\
\hline \multirow[b]{2}{*}{ Idade } & De 50 a 60 anos & 12 & 30 \\
\hline & $\begin{array}{c}\text { De } 60 \text { a } 70 \text { anos } \\
\text { De70 a } 80 \text { anos } \\
\text { Acima de } 80 \text { anos }\end{array}$ & $\begin{array}{c}18 \\
6 \\
4 \\
\end{array}$ & $\begin{array}{l}45 \\
15 \\
10 \\
\end{array}$ \\
\hline Gênero & $\begin{array}{l}\text { Masculino } \\
\text { Feminino }\end{array}$ & $\begin{array}{l}18 \\
22\end{array}$ & $\begin{array}{l}45 \\
55\end{array}$ \\
\hline
\end{tabular}




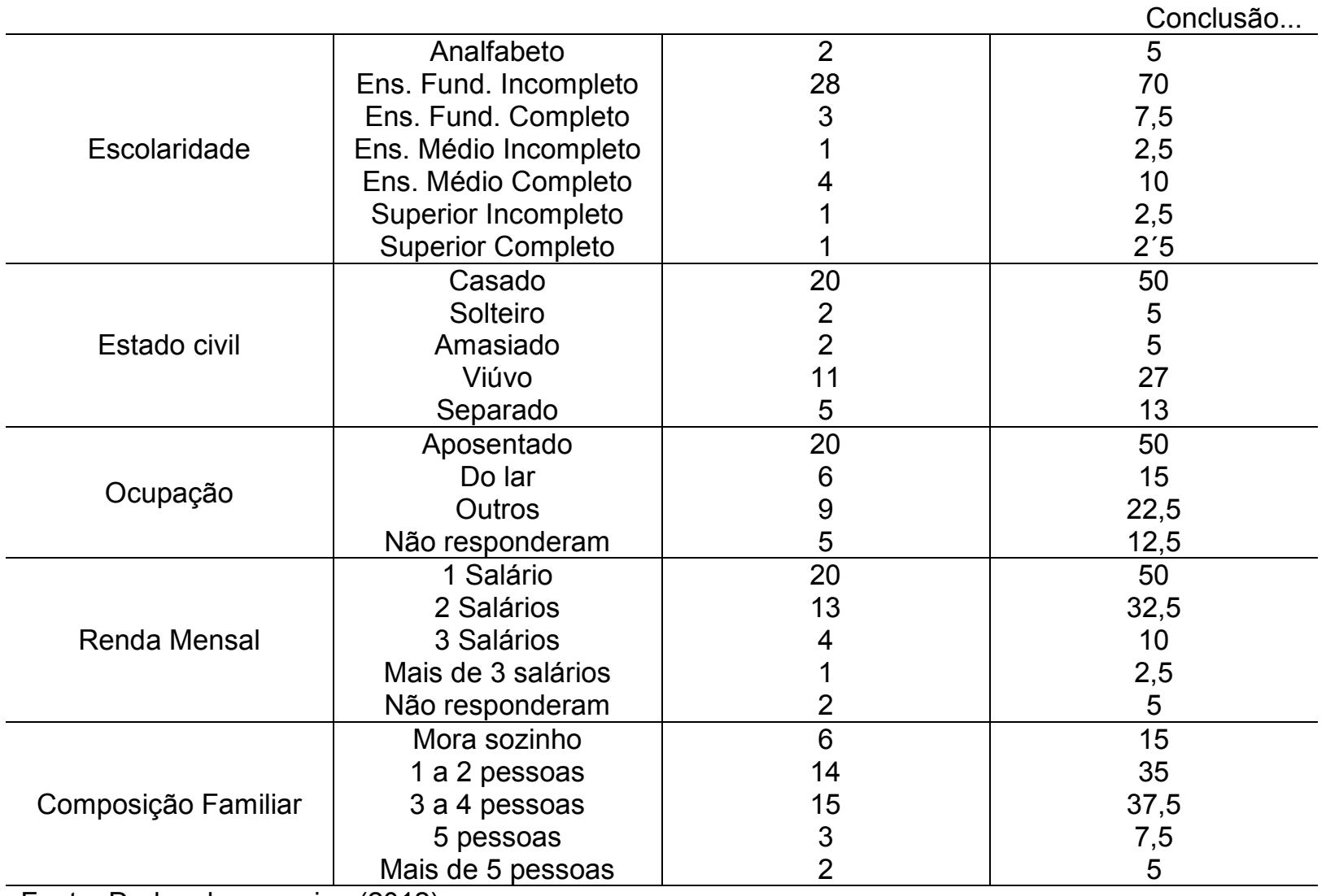

Fonte: Dados da pesquisa (2012)

Ao analisar a tabela 2, observa-se que a idade predominante dos entrevistados varia entre 60 e 70 anos com 45\% (18); em seguida os hipertensos com idade entre 50 a 60 anos alcançando $30 \%(n=12)$; de 70 a 80 anos são 15\% $(n=6)$ porém o que chama atenção é os $10 \%(n=4)$ de hipertensos acima de 80 anos, pois caracteriza a tendência atual de aumento da expectativa de vida da população.

Em relação ao gênero a diferença não é significativa, pois $45 \%(n=18)$ são do gênero masculino e 55\% $(n=22)$ do gênero feminino. De acordo com as Diretrizes Brasileiras de Hipertensão (2010 apud OLIVEIRA, 2011) as estimativas de hipertensão apresentam variações em função de diferentes critérios de classificação e instrumentos de medida utilizados. Mas pode se afirmar que a prevalência ocorre na mulher, pois, acaba se expondo a situações especiais que por si só contribuem para o surgimento de HAS - o uso de contraceptivo oral, a gestação e a própria menopausa, como exemplos.

Em relação à escolaridade, o que chama atenção é que ainda encontrou-se $5 \%(n=2)$ de analfabetos; $70 \%(n=28)$ também se destacam por possuir o ensino fundamental incompleto. Conforme as literaturas, isso demonstra que pode haver 
um déficit no entendimento em relação a muitas orientações, inclusive sobre a correta utilização de medicações.

Em relação ao estado civil encontrou-se que $50 \%(n=20)$ casados; $27 \%(n=11)$ viúvos; $13 \%(n=5)$ separados; $5 \%(n=2)$ solteiros e $5 \%(n=2)$ amasiado. Ainda que a metade da amostra apresenta estado civil como casados, observa-se que uma percentagem expressiva está na condição de viúvo, isto pode ser atribuído à idade, uma vez que 70\% ( $n=28)$ estão acima de 60 anos e, no Brasil, são considerados idosos e, segundo as literaturas esta é a fase da vida em que mais acontecem as perdas familiares, principalmente dos companheiros.

Em relação à ocupação, $50 \%(n=20)$ estão aposentados, que é justificado também pela idade em que se encontram; $15 \%(n=6)$ trabalham somente nas ocupações caseiras; $22,5 \%(n=9)$ relataram outras atividades, entre as quais 0 trabalho autônomo e, 12,5\% (n=5) não responderam.

Referente à renda mensal, $50 \%(n=20)$ recebe um salario mínimo; $32,5 \%$ $(n=13)$ recebe 02 salários mínimos; $10 \%(n=4)$ em torno de 03 salários; $2,5 \%(n=1)$ recebem mais de 03 salários mínimos e outros $5 \% \quad(n=2)$ não responderam a questão. É preocupante a questão de metade da amostra receber 01 salário mínimo, pois isto pode dificultar o acesso a insumos diversos para o lar, produtos de uso pessoal, podendo interferir até mesmo na qualidade da alimentação e moradia, o que tem influência direta nas condições de saúde.

Quanto à composição familiar, 37,5\% $(\mathrm{n}=15)$ residem com 03 a 04 pessoas na mesma casa; 35\% $(n=14)$ residem em 02 pessoas; $15 \%(n=6)$ residem sozinhos; $7,5 \%(n=3)$ com 05 pessoas e $5 \%(n=2)$ moram com mais de 05 pessoas. $O$ fato de que $15 \%$ residem sozinhos é preocupante, pois são pessoas idosas que podem encontrar certas dificuldades em tomar suas medicações nas doses e horários corretos.

Ao analisar as respostas da questão 08 quanto ao conhecimento de cada um sobre a hipertensão arterial, $25 \%(n=10)$ associaram a hipertensão como causador de AVC, Infarto e ter influencia sobre o sistema nervoso, que quando alterado provoca a hipertensão; $20 \%(n=8)$ associaram à má alimentação e falta de exercício físico; $12,5 \%(n=5)$ relataram que hipertensão é uma doença grave; $17,5 \%(n=7)$ disseram que é a elevação da pressão e outros $25 \%(n=10)$ desconhecem sobre a doença. 
Pierin et al. (2011), ressalta que o conhecimento sobre a doença e o tratamento da mesma é um dos fatores que pode contribuir no controle da hipertensão arterial, que indiretamente está ligado também à adesão ao tratamento.

Gráfico 5 - Referente ao tempo que é hipertenso

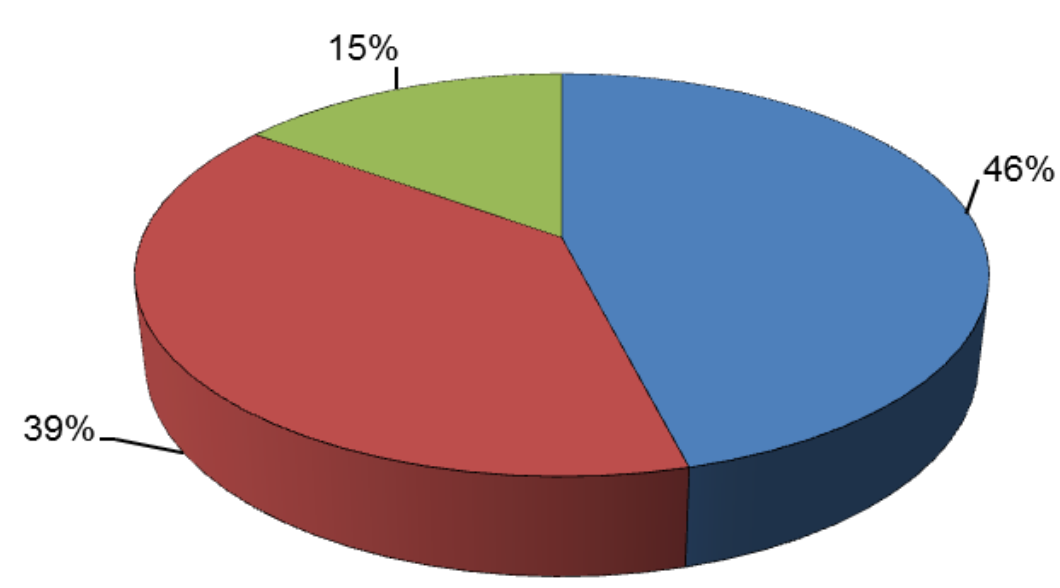

口De 1 a 10 anos aDe 11 a 20 anos aAcima de 21 anos

Fonte: Dados da pesquisa (2012)

Ao analisar este gráfico 05, observa-se que $46 \%(n=18)$ dos hipertensos são portadores de hipertensão entre 1 a 10 anos; outros 39\% (n=15) são portadores de 10 a 20 anos, e 15\% (n=6) são portadores à mais de 20 anos.

A hipertensão arterial sendo uma doença crônica exige tratamento medicamentoso e não medicamentoso para toda a vida e a cronicidade pode interferir diretamente na vida do paciente. A autoestima pode ser abalada, pelo aumento da probabilidade de possíveis complicações, em consequência disso o estado emocional se altera o que pode levar a emoções negativas como depressão e ansiedade Curtin et al. (1990 apud GUSMÃO; PIERIN, 2009).

Buscou-se saber o conhecimento que os hipertensos participantes da pesquisa têm sobre os medicamentos que utilizam, as respostas estão no gráfico 6 , a seguir. 
Gráfico 6 - Referente ao conhecimento sobre os medicamentos que utilizados para hipertensão

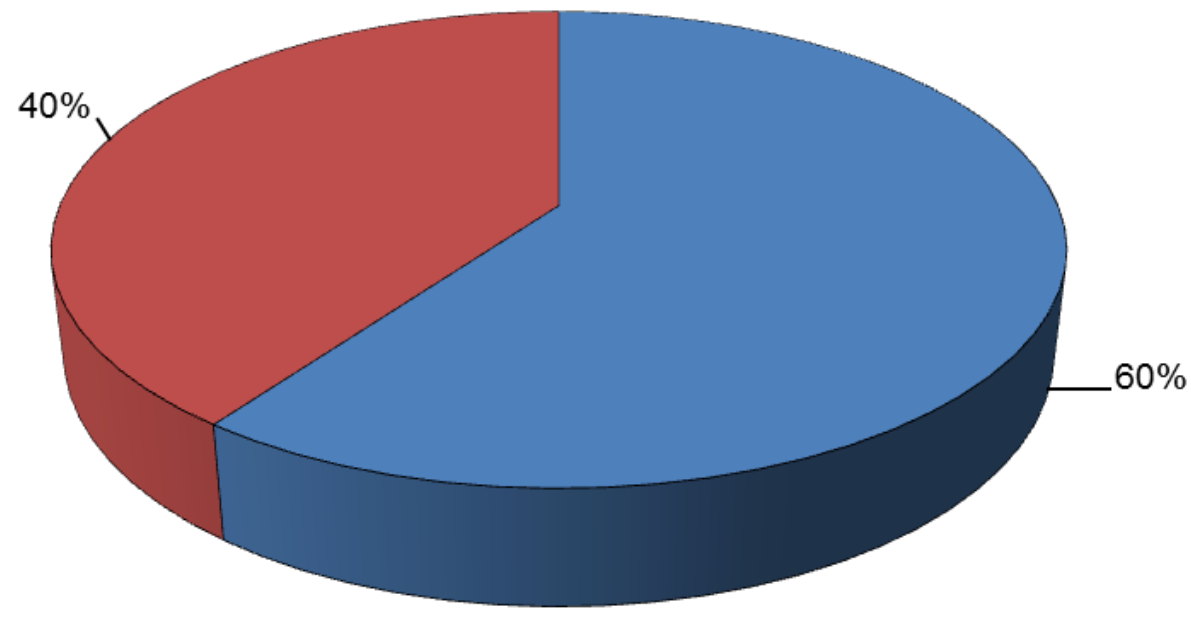

口Sim םNão

Fonte: Dados da pesquisa (2012)

Nota-se que $60 \%(n=24)$ conhecem a medicação que utilizam, como pode-se confirmar nas transcrições das respostas a seguir:

"Sim, pois são indispensáveis para controlar a pressão" (Entrevistado N 19. 16, Set., 2012, Sic).

"Sim, conheço o nome das medicações" (Entrevistados $\mathrm{N}^{\circ}$ 03, 15, 24, 31. 16 Set., 2012, Sic).

"Sim, sei que são medicações para a pressão e para o sangue" (Entrevistado №13. 17, Set., 2012, Sic).

Dos $40 \%$ que disseram que não conhecem a medicação utilizada para hipertensão Arterial, as respostas mais significativas foram:

"Não, mas sei que não faz mal tomar a medicação" (Entrevistado $N^{\circ}$ 09. 17, Set., 2012, Sic).

"Não, preciso de ajuda para usar a medicação" (Entrevistado № 27. 18, Set., 2012, Sic).

A hipertensão arterial exige tratamento e controle com isso deve ocorrer mudanças em relação a dieta, ingestão de medicamentos e o estilo de vida. Estas alterações podem comprometer a qualidade de vida, se não houver orientações adequadas em relação ao tratamento e o reconhecimento das complicações que 
podem ocorrer em consequência da patologia (BRUSSELS, 2008 apud MIRANZ, et al., 2008).

Hasford (1992) e Wilson et al. (2002, apud Mion, 2012), afirmam que o conhecimento sobre a doença e o tratamento deve ser uma situação considerada no contexto da adesão ao tratamento. Ressaltam também que os hipertensos possuem a informação sobre seu problema de saúde, porem não estão devidamente controlados. A diferença entre ter informação sobre sua doença e tratamento e conseguir controlar a pressão arterial aponta a diferença essencial entre conhecimento e adesão.

Gráfico 7 - Referente a quem recorrem quando têm dúvidas

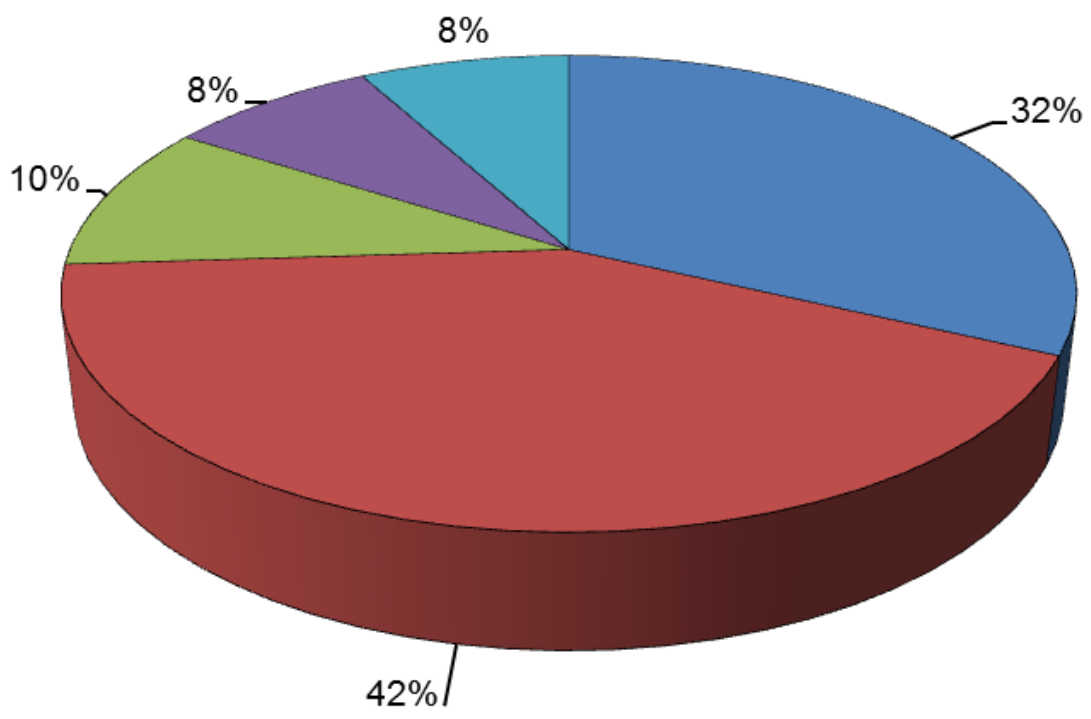

口Médico aEquipe de ESF $\quad$ Aos ACS $\square$ Aos familiares aNão tenho dúvidas

Fonte: Dados da pesquisa (2012)

Dos hipertensos $42 \%(n=17)$ responderam que quando tem alguma duvida sobre suas medicações recorrem a algum dos componentes da ESF ou PACS; $32 \%$ $(n=13)$ recorrem ao médico; $10 \%(n=4)$ responderam que perguntam aos ACS; $8 \%$ $(n=3)$ recorrem aos familiares e outros $8 \%(n=3)$ dizem não terem nem um tipo de duvida em relação às medicações.

Souza et al. (1994) afirmam que trabalhar em equipe demonstra ao paciente que uma pessoa só não poderá atender a todas as suas necessidades, a equipe além de proporcionar melhores cuidados ao paciente, também dispõe de melhores condições de trabalho para todos. 
Segundo Fáe et al. (2006 apud GUEDES et al., 2011) para que ocorra a adesão ao tratamento de doenças crônicas, a família é a base social que ajuda o familiar a dar continuidade correta ao tratamento, incentivando e acompanhando o tratamento junto ao serviço de saúde e auxiliando nas atividades físicas a na tomada dos medicamentos.

Ao analisar o gráfico 11, a seguir, percebe-se que 40\% (n=16) dos hipertensos dizem não receber orientações dos ACS e, outros 60\% $(n=24)$ recebem orientações.

Gráfico 8 - Referente as orientações realizadas pelos ACS aos usuários.

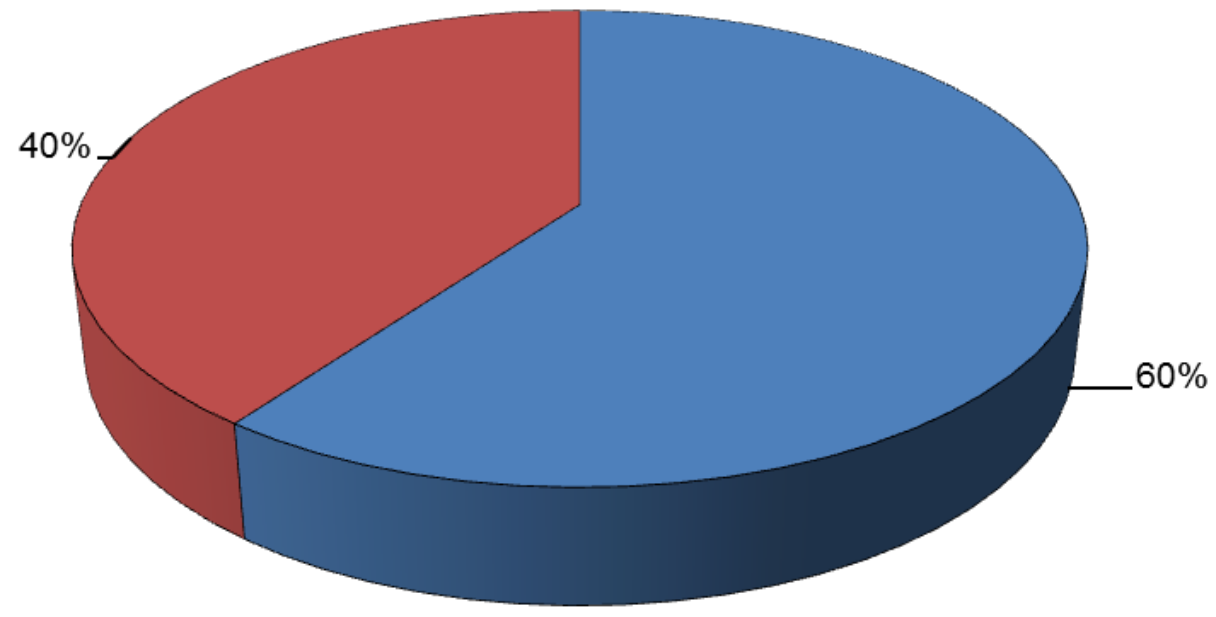

口Recebem orientações $\quad$ aNão recebem orientações

Fonte: Dados da pesquisa (2012)

Dos que recebem as orientações citadas são as seguintes:

"Falam sobre o remédio e a pressão alta" (Entrevistado $N^{\circ} 31$, Set., 2012, Sic).

"Orientam a verificar a pressão, e orientam sobre alimentação e higiene pessoal. (Entrevistado $N^{\circ} 40$, Set., 2012, Sic).

"Orientam sobre a verificação da pressão, alimentação e exercícios físicos" (Entrevistado $\mathrm{N}^{\circ}$ 39, Set., 2012, Sic).

"Orientam sobre o uso correto das medicações e a manter uma alimentação saudável" (Entrevistado $\mathrm{N}^{\circ} 13$. Set., 2012, Sic). 
"Orientam sobre os medicamentos certos nas horas certas" (Entrevistado $\mathrm{N}^{\circ}$ 35. Set., 2012, Sic).

"Orientam a não deixar de faltar as medicações e não deixar de toma-las" (Entrevistado $\mathrm{N}^{\circ}$ 34. Set., 2012, Sic).

"Orientam a medir a pressão arterial, e verificam se estamos tomando certo os remédios" (Entrevistado $N^{\circ} 32$. Set., 2012, Sic).

"Orientam como tomar as medicações, perguntam se estou precisando de consulta, exames ou vacinas" (Entrevistado $N^{\circ} 22$. Set., 2012, Sic).

Guedes, et al. (2011), afirmam que a hipertensão arterial sendo uma doença crônica, e ainda incurável, exige várias mudanças no estilo de vida, para que haja melhor controle. Porém estas alterações dependem da decisão de cada individuo. A mudança no estilo de vida é apontada como mudanças na dieta, controle na ingestão de álcool, parar de fumar, controle do peso corpóreo, realização de atividades físicas. Ligado a isso o fato das pessoas não sentirem nenhum sintoma quando a pressão está controlada acabam achando desnecessário o uso das medicações.

Ao analisar o próximo gráfico (12), tem-se que 92\% $(n=37)$ dos hipertensos relatam que ao solicitar o serviço do ACS são correspondidos, 5\% $(n=2)$ dizem nunca ter precisado do trabalho do ACS, e $3 \%(n=1)$ relatam que solicitaram o serviço e não foram correspondidos.

Gráfico 9 - Referente às solicitações de serviços, se são atendidos pelos ACS

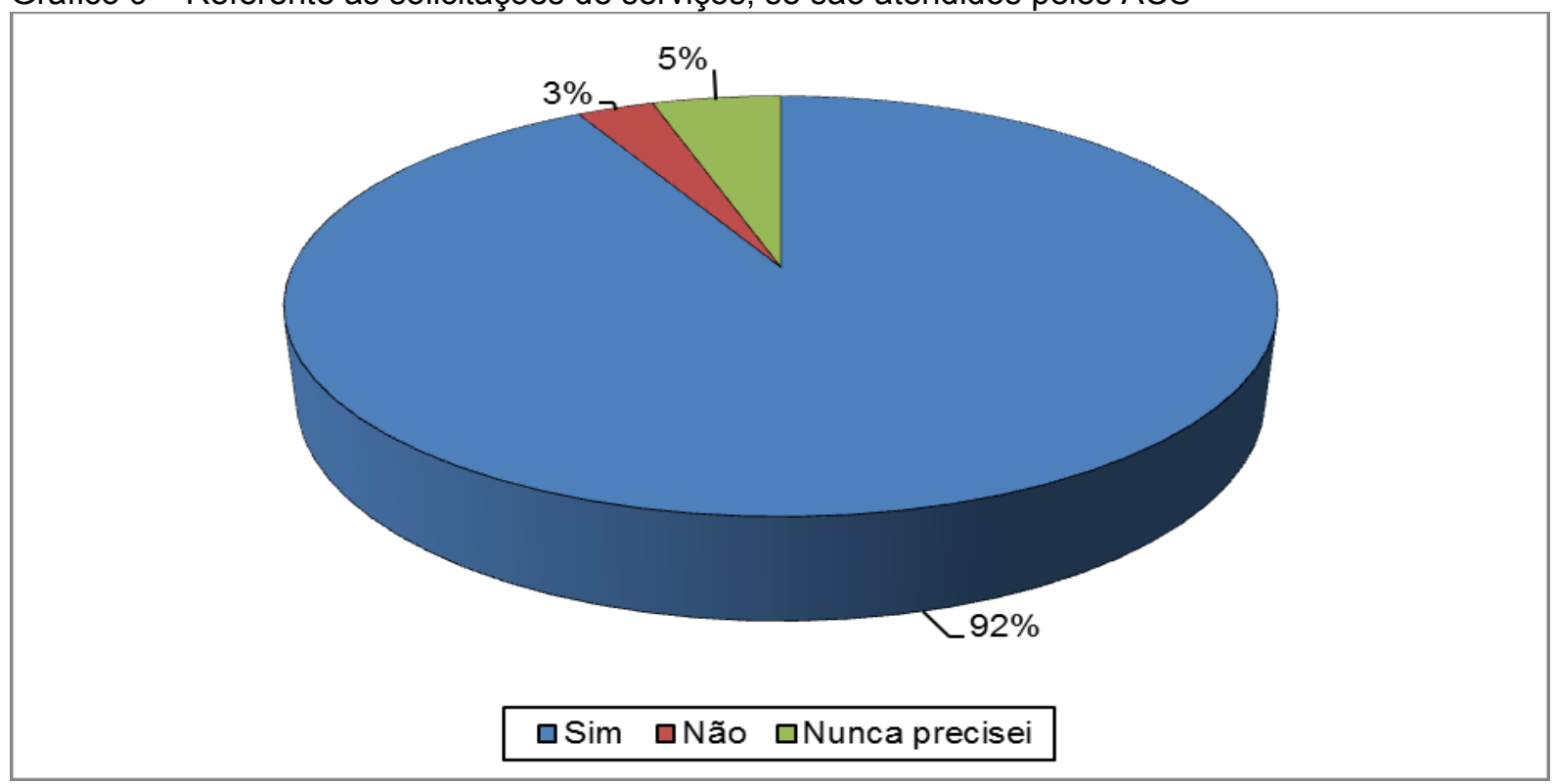

Fonte: Dados da pesquisa (2012)

Ágora: R. Divulg. Cient., v. 18, n. 2, p. 2-29, dez. 2011 (ISSN 2237-9010) 
De acordo com Brasil (1998 apud OLIVEIRA, et al., 2010) entre as atribuições dos ACS, destaca-se a realização de orientações às famílias para a correta utilização dos serviços de saúde e o repasse de informações para a equipe de saúde apontando a dinâmica social da comunidade, suas disponibilidade e necessidades.

Sendo assim, ressalta-se a importância do ACS frente as necessidades da população, por isso o mesmo deve ter visão das necessidades da comunidade proporcionando sempre melhoria no atendimento e encaminhamento correto aos serviços de saúde. Como resultado da pesquisa apontou que $3 \%$ dos entrevistados solicitaram o serviço do ACS e não foram atendimentos em contra partida $92 \%$ afirmam que sempre foram atendidos, isso demonstra que realmente o trabalho dos ACS estão sendo efetivos.

\section{CONCLUSÃO}

Com os resultados alcançados neste estudo, compreende-se que o papel do Agente Comunitário de Saúde é de suma importância para que ajudem a população a aderirem ao tratamento medicamentoso, aqui em questão, os hipertensos. A hipertensão sendo uma doença crônica, silenciosa e que consequentemente pode causar grandes males à saúde das pessoas, acaba sendo também um importante problema de saúde publica, que exige medidas de controle para conter sua progressão e diminuir o alto índice de mortalidade.

É importante destacar que as pessoas têm adoecido e morrido mais por doenças crônicas, e que o trabalho do agente comunitário de saúde deve ser valorizado, pois lhe são designadas funções estratégicas e complexas, direcionadas à população no sentido de orientar para evita-las.

Sabe-se também que a escolaridade exigida para poder atuar como ACS é o ensino fundamental, e que talvez se a escolaridade exigida fosse o ensino médio poderia ser-Ihes atribuídas outras competências e, com certeza os resultados seriam melhores.

No entanto a adesão ou não ao tratamento depende da decisão do portador da doença. Em geral a equipe de saúde assume a responsabilidade de ajudar essas pessoas para que compreendam sobre os cuidados com a doença e a importância 
em realizar um tratamento medicamentoso correto. Para que se consiga chegar a algum resultado a iniciativa deve partir da ESF, e trabalhar junto, pois de que adianta - ACS prestar orientações sem ter sido especificamente capacitado para isso. Entende-se que o enfermeiro deve capacitar os ACS para que consigam realmente ajudar os pacientes.

O elo que os ACS acabam tendo com a população, morando da mesma área que atua promove maior facilidade em identificar os problemas exposto naquela área. Destaca-se também que o enfermeiro, por ser um profissional com mais responsabilidades e coordenador de sua ESF, acaba não tendo tempo disponível para visitar frequentemente os domicílios, assim entende-se que o agente é a peça chave para trazer até a equipe as possíveis intercorrências encontradas no dia-a-dia da família.

$\mathrm{Na}$ pesquisa encontra-se que os ACS julgam-se importantes para orientar sobre o tratamento medicamentoso anti-hipertensivo, colaborando para a sua adesão, ainda que para alguns falte conhecimento.

Quanto aos hipertensos, encontra-se que a maioria adere ao tratamento, porém os $40 \%$ que tem dificuldades relaciona-se ao fato de terem duvidas sobre como realiza-la ou pouco conhecimento sobra a hipertensão, mas que procuram ajuda dos diversos profissionais e/ou familiares.

Espera-se que este trabalho ajude os profissionais de saúde a compreenderem a importância do trabalho do ACS e sua contribuição para a adesão ao tratamento medicamentoso anti-hipertensivo, pois são profissionais que cooperam muito para a saúde e bem estar das pessoas.

\section{REFERÊNCIAS}

ALBUQUERQUE, Beatriz de Mello, MENDES, Narjara Fernandes, YUNES, Maria Angela Mattar. Percepções e crenças de agentes comunitários de saúde sobre resiliência em famílias monoparentais pobres.2005. Disponível em:

<http://www.scielo.br/pdf/tce/v14nspe/a02v14nspe.pdf>. Acesso em: set.2012.

BARBOSA, Vanessa Baliego de Andrade; FERREIRA, Maria de Lourdes Silva Marques; BARBOSA, Pedro Marco Karan. Educação permanente em saúde: uma estratégia para a formação dos agentes comunitários de saúde. Rev. Gaúcha Enferm., v. 33, n. 1, p. 56-63, 2012. Disponível em: <http://dx.doi.org/10.1590/ S1983-14472012000100008>. Acesso em: 10 set. 2012. 
BERVIAN, Pedro. A.; CERVO, Amado. L. Metodologia científica. 4.ed. São Paulo: Makron Books, 1996.

BRASIL. Ministério da Saúde. Conselho Nacional de Saúde. Resolução $\mathbf{n}^{\circ}$ 259, de 4 de dezembro de 1997. Disponível em: <http://bvsms.saude.gov.br/bvs/saudelegis/ cns/1997/res0259_04_12_1997.html>. Acesso em: 15 set. 2012.

. Ministério da Saúde. Perfil de Competências profissionais do ACS. 2002.

Disponível em: <portal.saude.gov.br/portal/arquivos/pdf/

anexo_perfil_competencias_acs.pdf>. Acesso em: 22 ago. 2012.

. Ministério da Saúde. Portaria n 648P/GM de 28 de março de 2006.

Aprova a Política Nacional de Atenção Básica, estabelecendo a revisão de diretrizes e normas para a organização da Atenção Básica para o Programa Saúde da Família (PSF) e o Programa Agentes Comunitários de Saúde (PACS). Disponível em: <www.saudeprev.com.br>. Acesso em: 10 out. 2010.

. Ministério da Saúde. Programa Saúde da Família 2012. Portal da Saúde. Disponível em: <http://portal.saude.gov.br/portal/saude/ cidadão/area.cfm?id_area=149>. Acesso em: 15 maio 2012.

. Ministério da Saúde. Secretaria de Atenção à Saúde. Departamento de Atenção Básica. Guia prático do agente comunitário de saúde. Brasília: Ministério da Saúde, Secretaria de Atenção à Saúde, Departamento de Atenção, 2009.

CORNU, Jules. Sobre a pressão arterial sistólico \& diastólico números. 2012. Disponível em: <http://www.appforce.net/sobre-a-pressao-arterial-sistolico-diastoliconumeros.html>. Acesso em: 16 set. 2012.

COSTA, Lílian; CARVALHO, Kênia Mara Baiocchi de. Nutrição cínica do adulto. 2.ed. Barueri: Manole, 2005. cap.8, p.149-171.

FIGUEIREDO, Nébia M. A. Ensinando a cuidar em saúde pública. 1.ed. São Caetano do Sul: Yendis, 2005.

FORTES, Paulo Antonio de Carvalho; SPINETTI, Simone Ribeiro. O agente comunitário de saúde e a privacidade das informações dos usuários. Cad. Saúde Pública, Rio de Janeiro, v. 20, n. 5, p. 1328-1333, set./out., 2004. Disponível em: <http://www.scielosp.org/pdf/csp/v20n5/27.pdf>. Acesso em: 11 out. 2011.

GUEDES, Maria Vilani Cavalcante et al. Barreiras ao tratamento da hipertensão arterial. Rev. bras. enferm., v. 64, n. 6, p. 1038-1042, 2011. Disponível em: <http://dx.doi.org/10.1590/S0034-71672011000600008>. Acesso em: 23 maio 2012.

GUEDES, Jose da Silva; SANTOS, Rosa Maria Barros dos; DI LORENZO, Rosicler A. Viegas. A implantação do Programa de Saúde da Família (PSF) no Estado de São Paulo (1995-2002). Saude soc., São Paulo, v. 20, n. 4, dez. 2011. Disponível em <http://www.scielo.br/scielo.php?script=sci_arttext\&pid=S010412902011000400006\&lng=pt\&nrm=iso>. Acesso em: 23 out. 2012. 
GUIMARÃES, José Maria Ximenes et al. Concepções dos agentes comunitários de saúde sobre sua prática no programa de saúde da família. Rev. APS, v.10, n.2, p. 128-136, jul./dez. 2007. Disponível em: <http://www.ufjf.br/nates/files/2009/12/ 05concepcao.pdf. >. Acesso em: 10 set. 2012.

GUSMAO, Josiane Lima de; PIERIN, Angela Maria Geraldo. Instrumento de avaliação da qualidade de vida para hipertensos de Bulpitt e Fletcher. Rev. esc. enferm. USP, v. 43. N.spe, p. 1034-1043, 2009. Disponível em: <http://dx.doi.org/10.1590/S0080-62342009000500007>. Acesso em: 20 ago. 2012.

HILDEBRAND, Stella Maris; SHIMIZU, Helena Eri. Percepção do agente comunitário sobre o Programa Família Saudável. Rev. bras. enferm., v. 61, n. 3, p. 319-324, 2008. Disponível em: <http://dx.doi.org/10.1590/S0034-71672008000300007>. Acesso em: 15 set. 2012.

JUGDAR, Patricia; LAUTENSCHLAEGER, Denise; MANI, Felipe Eduardo Miralé. Reflexão sobre a promoção da saúde na visão dos atores sociais do programa saúde da família. São Paulo: Anhanguera Educacional, 2009.

LIMA, Ariane Netto de; SILVA, Lucia; BOUSSO, Regina Szylit. A visita domiciliária realizada pelo agente comunitário de saúde sob a ótica de adultos e idosos. Saúde soc. V. 19, N. 4, P. 889-897, 2010. Disponível em: <http://dx.doi.org/10.1590/S0104$12902010000400015>$. Acesso em: 12 ago. 2012.

MARQUES, Dalvani; SILVA, Eliete Maria. A enfermagem e o Programa Saúde da Família: uma parceria de sucesso?. Rev. bras. enferm., v. 57, n. 5, p. 545-550, 2004. Disponível em: <http://dx.doi.org/10.1590/S0034-71672004000500006>. Acesso em: 12 set. 2012.

MION JR, Décio et al. Hipertensão arterial na cidade de São Paulo: prevalência referida por contato telefônico. Arq. Bras. Cardiol., v. 95, n. 1, p. 99-106, 2010. Disponível em: <http://dx.doi.org/10.1590/S0066-782X2010005000051>. Acesso em 20 maio 2012.

MIRANZI, Sybelle de Souza Castro et al . Qualidade de vida de indivíduos com diabetes mellitus e hipertensão acompanhados por uma equipe de saúde da família. Texto contexto - enferm., Florianópolis, v. 17, n. 4, dez. 2008. Disponível em: <http://www.scielo.br/scielo.php?script=sci_arttext\&pid=S010407072008000400007\&lng=en\&nrm=iso>. Acesso em: 10 ago. 2012.

MOURA, Denizielle de Jesus Moreira et al. Cuidado de enfermagem ao cliente com hipertensão: uma revisão bibliográfica. Rev. bras. enferm., v. 64, n. 4, p. 759-765, 2011. Disponível em: <http://dx.doi.org/10.1590/S0034-71672011000400020>. Acesso em: 12 maio 2012.

OLIVEIRA, Jeane Freitas de; MCCALLUM, Cecília Anne; COSTA, Heloniza Oliveira Gonçalves. Representações sociais de Agentes Comunitários de Saúde acerca do consumo de drogas. Rev. esc. enferm. USP, São Paulo, v. 44, n. 3, set. 2010. Disponível em: <http://www.scielo.br/scielo.php?script=sci_arttext\&pid=S008062342010000300009\&lng=en\&nrm=iso>. Acesso em: 05 set. 2012. 
OLIVEIRA, Liliane Marta mendes; MARTINS, Aurelia Gomes, FREITAS, Daniel Antunes. Hipertensão arterial: uma realidade a ser enfrentada. Revista Digital. Buenos Aires, v. 16, n. 161, out. 2011. Disponível em:

$<$ http://www.efdeportes.com/efd161/hipertensao-arterial-uma-realidade-a-serenfrentada.htm>. Acesso em: 10 set. 2012.

OLIVEIRA, Silvio L. Tratado de metodologia científica. 2.ed. São Paulo: Pioneira, 2002.

PIERIN, Angela Maria Geraldo, SILVA, Giane Christina Alves da, AGENA, Fabiana. Monitorização residencial da pressão arterial: atualidades e papel do enfermeiro.

Rev.Esc enfermagem USP, São Paulo, v. 45, n.1, mar. 2011. Disponível em: <http://www.scielo.br/pdf/reeusp/v45n1/36.pdf>. Acesso em: 10 maio 2012.

PORTAL PIÊN. Historia da Cidade de Piên, 2011. Disponível em:

<http://www.portalpien.com.br/a_cidade/historia.php>. Acesso em: 06 ago. 2012.

RIBEIRO, Amanda Gomes et al . Hipertensão arterial e orientação domiciliar: o papel estratégico da saúde da família. Rev. Nutr., Campinas, v. 25, n. 2, abr. 2012. Disponível em: <http://www.scielo.br/scielo.php?script=sci_arttext\&pid=S141552732012000200009\&lng=en\&nrm=iso>. Acesso em: 12 set. 2012.

SAKATA, Karen Namie; MISHIMA, Silvana Martins. Articulação das ações e interação dos Agentes Comunitários de Saúde na equipe de Saúde da Família. Rev. esc. enferm. USP, São Paulo, v. 46, n. 3,p. 665-672, jun. 2012. Disponível em: $<$ http://www.scielo.br/scielo.php?script=sci_arttext\&pid=S008062342012000300019\&Ing=en\&nrm=iso>. Acesso em: 10 set. 2012.

SARQUIS, Leila Maria Mansano et al. A adesão ao tratamento na hipertensão arterial: análise da produção científica. Rev. esc. enferm. USP, São Paulo, v. 32, n. 4, p. 335-353, dez. 1998. Disponível em: <http://www.scielo.br/scielo.php?script= sci_arttext\&pid=S0080-62341998000400007\&Ing=en\&nrm=iso>. Acesso em: 10 set. 2012.

SHIMIZU, Helena Eri; ROSALES, Carlos. As práticas desenvolvidas no Programa Saúde da Família contribuem para transformar o modelo de atenção à saúde?. Rev. bras. enferm., Brasília, v. 62, n. 3, p. 424-429, jun. 2009. Disponível em: $<$ http://www.scielo.br/scielo.php?script=sci_arttext\&pid=S003471672009000300014\&lng=en\&nrm=iso>. Acesso em: 10 set. 2012.

SOUZA, Ana Luiza Lima; JARDIM, Paulo César B. Veiga. A Enfermagem e o paciente hipertenso em uma abordagem multiprofissional: relato de experiência. Rev. Latino-Am. Enfermagem, Ribeirão Preto, v. 2, n. 1, p. 5-17, jan. 1994. Disponível em: <http://www.scielo.br/scielo.php?script=sci_arttext\&pid=S0104$11691994000100002 \&$ Ing=en\&nrm=iso>. Acesso em: 10 set. 2012. 